\title{
Avaliação de metais em sedimentos da micro bacia Tietê Batalha por meio do Sistema de Informação Geográfica (SIG)
}

Evaluation of metals in sediments of the Tietê Batalha basin using the Geographic Information System (GIS)

Evaluación de metales en sedimentos de la microcuenca Tietê Batalla por medio del Sistema de Información Geográfica (SIG)

Ana Maria Taddei Cardoso de Barros Mestre, UNESP, Brasil ana.cardoso@unilins.edu.br

Paulo Cesar Lodi Professor Doutor, UNESP, Brasil plodi@feb.unesp.br

José Eduardo Taddei Cardoso

Graduado, UNESP, Brasil. joseeduardotc@gmail.com 


\section{ANAP Brasil \\ ISSN 1984-3240 \\ v. 10, n. 21}

RESUMO

Este trabalho avaliou a qualidade ambiental da micro bacia do Tietê Batalha utilizando o Sistema de Informação Geográfica (SIG) por meio do qual foi possível monitorara a quantidade de metais presentes nos sedimentos. Todos os procedimentos envolvidos para a entrada, manipulação e armazenamento dos dados foram realizados através de equipamentos específicos (como por exemplo, receptores GPS com sonar para os levantamentos planialtimétricos). Imagens digitais foram utilizadas para possibilitar a combinação da localização dos pontos e da concentração de cada elemento analisado. A área de estudo situa-se na bacia Tietê Batalha, próxima à cidade de Lins (SP). Foram definidos os corpos hídricos que seriam monitorados, os pontos e a frequência das coletas. No total foram sete córregos definidos e os pontos de coleta foram marcados por GPS. Os dados com as concentrações dos metais foram obtidos através de coleta em triplicata de amostras de sedimentos em pontos próximos à margem e a jusante dos afluentes próximos a barragem da Usina Hidrelétrica de Promissão. As principais conclusões mostram que a ferramenta SIG mostrou-se muito eficiente no propósito de auxiliar na avaliação ambiental da qualidade dos sedimentos da micro bacia do Tietê-Batalha. Dentre os pontos analisados, dois (ponto 2 e o ponto 6) apresentaramse como os mais vulneráveis a contaminação devido às proporções elevadas em todos os elementos analisados. 0 tipo de solo e o uso e ocupação da região contribuem com o aumento da concentração de metais nos sedimentos.

PALAVRAS-CHAVE: Sistema de informação geográfica. Bacia hidrográfica Tietê Batalha. Análise de metais.

\section{ABSTRACT}

This research evaluated the environmental quality of the Tietê Batalha micro basin using the Geographic Information System (GIS) through which it was possible to monitor the amount of metals present in the sediments. All procedures involved in data entry, manipulation and storage were performed using specific equipment (such as GPS receivers with sonar for planialtimetric surveys). Digital images were used to enable the combination of the location of the points and the concentration of each element analyzed. The study area is located in the Tietê-Batalha basin, near the city of Lins (SP). The water bodies that were to be monitored, the points and the frequency of the collections were defined. In total there were seven defined streams and the collection points were marked by GPS. The data with the concentrations of the metals were obtained by means of triplicate collection of sediment samples at points near the margin and downstream of the tributaries near the dam of the Promissão Hydroelectric Plant. The main conclusions show that the GIS tool was very efficient in the purpose of assisting in the environmental evaluation of the sediment quality of the Tietê Batalha micro basin. Among the analyzed points, Point 2 and Point 6 were the most vulnerable to contamination due to the high proportions in all the elements analyzed. The type of soil and the type of use and occupation of the region contribute to the increase of the concentration of metals in the sediments.

Keywords: Geographic Information System. Tietê Batalha hydrographic basin. Analysis of metals.

\section{RESUMEN}

Este trabajo evaluó la calidad ambiental de la micro cuenca del Tietê Batalla utilizando el Sistema de Información Geográfica (SIG) por medio del cual fue posible monitorear la cantidad de metales presentes en los sedimentos. Todos los procedimientos involucrados para la entrada, manipulación y almacenamiento de los datos se realizaron a través de equipos específicos (como por ejemplo, receptores GPS con sonar para los levantamientos planialtimétricos). Las imágenes digitales se utilizaron para permitir la combinación de la ubicación de los puntos y de la concentración de cada elemento analizado. El área de estudio se sitúa en la cuenca Tietê Batalha, cerca de la ciudad de Lins (SP). Se definieron los cuerpos hídricos que serían monitoreados, los puntos y la frecuencia de las colectas. En total fueron siete arroyos definidos y los puntos de recolección fueron marcados por GPS. Los datos con las concentraciones de los metales fueron obtenidos a través de la recolección en triplicada de muestras de sedimentos en puntos cercanos al margen y aguas abajo de los afluentes próximos a la represa de la Usina Hidroeléctrica de Promesa. Las principales conclusiones muestran que la herramienta SIG se mostró muy eficiente en el propósito de auxiliar en la evaluación ambiental de la calidad de los sedimentos de la micro cuenca del Tietê Batalha. Entre los puntos analizados, el punto 2 y el punto 6 se presentaron como los más vulnerables a la contaminación debido a las proporciones elevadas en todos los elementos analizados. El tipo de suelo y el tipo uso y ocupación de la región contribuyen con el aumento de la concentración de metales en los sedimentos.

PALABRAS- CLAVE: Sistema de información geográfica. Cuenca hidrográfica Tietê Batalla. Análisis de metales 


\section{ANAP Brasil $_{\text {l }}$ \\ ISSN 1984-3240 \\ v. 10, n. 21}

\section{REVISTA CIENTIFICA 2017}

\section{INTRODUÇÃO}

A gestão de recursos ambientais, principalmente de recursos hídricos, tem sua evolução galgada na soma de modelos de desenvolvimento sustentáveis com a avaliação de impactos cumulativos e sinergéticos das intervenções antrópicas, facilitando a compreensão das interações entre diversos fatores, bem como a dinâmica dos processos naturais. A divisão das bacias hidrográficas surgiu como ferramenta facilitadora para o planejamento urbano e rural, bem como no cuidado com os recursos naturais (TUCCl, 2006). Cada bacia possui características econômicas, sociais e ambientais que interagem entre si nas inúmeras atividades que acontecem em seu território, resultando em diversos aspectos ambientais negativos que podem vir a deteriorar a sua qualidade hídrica.

Os impactos ambientais mais comuns causados pelas atividades antrópicas dentro da bacia hidrográfica estão intimamente ligados a perda de solo devido às mudanças do uso e ocupação, ausência de matas ciliares, utilização de agroquímicos sem planejamento, manejo do solo inadequado, entre outras. Desde a antiguidade, registros sobre poluição ambiental com metais são identificados em vários tipos de depósitos naturais, especialmente em camadas de gelo polar e sedimentos aquáticos. Os apontamentos ambientais de contaminação antrópica mais utilizados na atualidade são os sedimentos aquáticos devido a propriedade de agregar em si componentes de contaminação provenientes de diferentes meios como água, atmosfera e solo (NASCIMENTO, 2008). De acordo com POLETO (2005), metais são contaminantes ambientais estáveis e persistentes uma vez que não podem ser degradados ou destruídos no meio em que se encontram.

O Brasil possui diversas áreas em que a disponibilidade de recurso hídrico para abastecimento humano e industrial estão comprometidos devido às altas quantidades de substâncias tóxicas presentes nas águas subterrâneas, mananciais e lagos. Estudos realizados por Nascimento (2008) mostram que a bacia do rio Tietê possui várias áreas com problemas de contaminação devido a elevada atividade industrial, fato que compromete uma importante fonte de abastecimento de muitos municípios do estado de São Paulo. As causas de contaminação por metais nas águas do estado de São Paulo variam de acordo com a atividade econômica de cada região, podendo notar que no interior o maior impacto é proveniente de atividades agrícolas e uso de fertilizantes; e na grande São Paulo são os pólos industrias os que mais influenciam. Toda a carga poluidora gerada na capital é transportada pelo rio Tietê, afetando a qualidade das águas e consequentemente, dos sedimentos dos seus afluentes. Para auxiliar na avaliação ambiental utilizaram-se Sistemas de Informação Geográfica (SIG), que combinam ferramentas eficientes com a tecnologia das imagens de satélites, resultando em mapas temáticos que auxiliam no monitoramento das concentrações de contaminantes. Através do processamento de imagens de satélites realizadas por SIG é possível fazer com que a bacia hidrográfica se torne um excelente meio de se analisar e avaliar as condições ambientais de uma região, minimizando os impactos resultantes do processo de exploração, visando a sustentabilidade ambiental da área estudada. 


\section{ANAP Brasil \\ ISSN 1984-3240 \\ v. 10, n. 21}

REVISTA CIENTIFICA 2017

\subsection{QUALIDADE AMBIENTAL ASSOCIADA AOS SEDIMENTOS}

As associações dos metais com os sedimentos podem ocorrer de diversas maneiras como por adsorção nas partículas de superfície, ligação com carbonatos, podem estar isolados nos hidróxidos de ferro ou de manganês e associados a matéria orgânica e a sulfetos (SALOMONS \& FORSTNER, 1980).

A composição mineralógica de cada formação geológica é naturalmente variável, de maneira que a abundância dos elementos estará condicionada a formação das rochas que compõem a região estudada. Chama-se de geodisponibilidade a fração da espécie química de uma rocha que é passível de ser liberada na superfície terrestre por processos físicos, químicos ou biológicos, sendo esse valor dependente de fatores como topografia, clima e a estrutura geológica (LIMA, 2008).

Em trabalhos de monitoramento de contaminação em sedimentos deve-se analisar a composição geológica da região para posterior conclusão de índices dos contaminação. No Brasil existe uma regulamentação sobre critério de qualidade de sedimentos para fins de dragagem (Resolução CONAMA n³44/2004 - CONAMA, 2004) mas ainda não existem, apesar dos frequentes problemas com contaminação de sedimentos em rios e reservatórios, orientações especificas para diagnosticar o impacto de uma contaminação, formas de gerenciamento, bem como de minimização, estando a cargo do responsável pela poluição essas definições (ALMEIDA, 2010).

\subsection{CARACTERIZAÇÃO DA ÁREA DE ESTUDO: BACIA HIDROGRÁFICA TIETÊ- BATALHA}

O reservatório estudado faz parte da bacia hidrográfica denominada de Tietê-Batalha e, situase no centro do Estado de São Paulo, é identificada como Unidade de Gerenciamento de Recursos Hídricos 16 (UGRH 16), agrega 36 municípios e possui áreas de outros 14 municípios, cujas sedes localizam-se em UGRHI)s vizinhas (CARDOSO, 2014).

Segundo o Plano de recursos hídricos da UGRHI 16, esta bacia ocupa área de $13.149 \mathrm{Km}^{2} \mathrm{e}$ disponibiliza água de ótima qualidade e em quantidade abundante para o estado, fatores que favorecem o interesse de altos investimentos. Dois pontos fortes são a Hidrovia Tietê Paraná que faz parte do trecho estudado e a malha ferroviária, ambas utilizadas tanto para transportar minérios e combustíveis, quanto cargas em geral. Os cursos d'água que se destacam na região são os rios Tietê, Batalha, Dourado, dos Porcos e Ribeirão Barra Mansa (CBH Tietê-Batalha, 2010).

De acordo com levantamento realizado pelo Comitê de Bacia Hidrográfica Tietê Batalha, a característica dos sítios rochosos da região são de rochas sedimentares e vulcânicas, situados em uma fração transitória entre a formação da Serra Geral (basaltos) e Formação Adamantina (arenitos). A composição da litologia é basicamente de arenitos e argilitos com latossolo vermelho amarelo com distribuição generalizada, além de frações com podzólico vermelhoamarelo, características essas que classificam a área como de alta susceptibilidade aos processos erosivos (CBH TIETÊ-BATALHA, 2010). 


\section{ANAP Brasil \\ ISSN 1984-3240 \\ v. 10, n. 21}

\section{REVISTA CIENTIFICA 2017}

Os principais usos e ocupações do solo são de atividades urbanas, industriais e agroindustriais. Os municípios são de pequeno e médio porte, com indústrias nas áreas de produtos alimentícios como frigoríficos e laticínios, produção de matéria prima como usinas de açúcar e álcool e curtumes. Nas áreas rurais há cultivo de culturas que alimentam as indústrias como cana de açúcar, laranja, além de criação de bovinos, sendo alguns por confinamento.

Os impactos ambientais causados pelas atividades antrópicas dentro da bacia hidrográfica estão intimamente ligados a perda de solo devido às mudanças do uso e ocupação, ausência de matas ciliares, utilização de agroquímicos sem planejamento, manejo do solo inadequado, entre outras.

\subsection{SISTEMA DE INFORMAÇÃO GEOGRÁFICA (SIG) EM ESTUDOS AMBIENTAIS}

O surgimento dos SIG em estudos ambientais e agronômicos trouxe uma facilidade na compilação de dados e no monitoramento de áreas, uma vez que os fenômenos estudados e/ou avaliados normalmente ocorrem em extensas áreas, de maneira que levaria muito tempo para realizar os levantamentos, coletar os dados e compilá-los conjuntamente. Os SIGs são softwares que permitem armazenar, gerenciar, combinar dados espaciais, além de fornecerem ferramentas de análise para o usuário, sendo que alguns deles são de livre acesso e de fácil manipulação. Pode-se definir um SIG como um conjunto de programas cuja finalidade básica é coletar, armazenar, processar e analisar dados geográficos, possibilitando a interpretação do usuário de acordo com as necessidades do estudo realizado (CÂMARA,1988).

Os SIG são compostos de hardware, software, dados e pessoas, que juntos permitem a representação do mundo real em planos de informações. São muito utilizados para referenciar geograficamente um acontecimento e visualizar espacialmente variáveis como, por exemplo, um fenômeno natural ou antrópico através de uma análise espacial completa.

Os dados gerados por um monitoramento ambiental podem ser armazenados e trabalhados de acordo com os interesses do usuário permitindo, por exemplo, apresentar a quantificação e a situação em que se encontra determinado estudo através de registros anteriores. A Figura 1 ilustra as interfaces possíveis na combinação de camadas com diferentes informações.

Figura 1: Interfaces possíveis na combinação de camadas com informações diferentes.

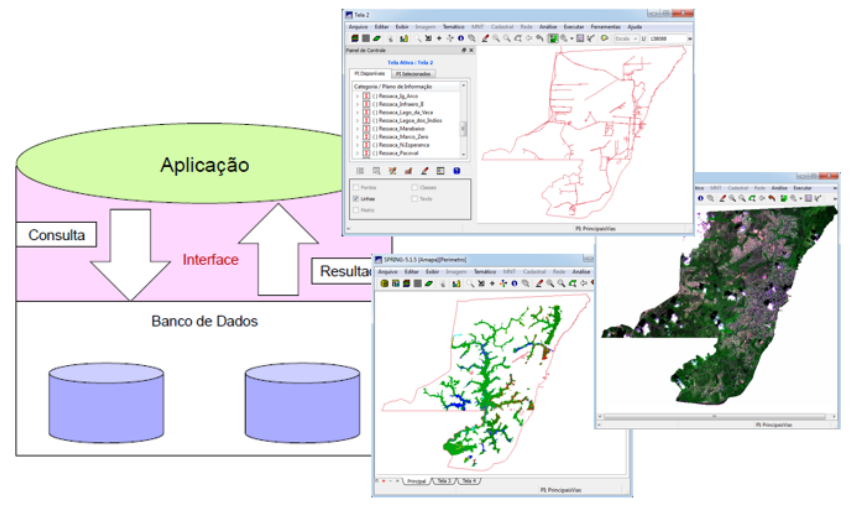

Fonte: CÂMARA, 2011 


\section{ANAP Brasil \\ ISSN 1984-3240 \\ v. 10, n. 21}

\section{REVISTA CIENTIFICA 2017}

\section{OBJETIVOS}

Avaliar a qualidade ambiental dos sedimentos da micro bacia do Tietê Batalha por meio do Sistema de Informação Geográfica (SIG).

\section{METODOLOGIA}

\subsection{EQUIPAMENTOS}

Neste estudo todos os procedimentos envolvidos para a entrada, manipulação e armazenamento dos dados foram realizados através dos seguintes equipamentos:

- Receptor GPS Garmin Echomap 50dv com sonar para os levantamentos planialtimétricos;

- Receptor GPS Garmin Etrex 20;

- Software para processamento Quantum GIS versão 2.18.9;

- Computador compatível com IBM-PC, com processador intel i5, 4 Gb de memória RAM, $500 \mathrm{~Gb}$ de HD e placa de vídeo Nvidia 9700.

- Sistema operacional Windows 7.

\subsection{CARTAS TOPOGRÁFICAS}

As imagens digitais utilizadas foram obtidas através do satélite Landsat 8 , bandas 3,4 e 5 , referentes ao ano de 2015, cedidas gratuitamente pelo INPE - Instituto Nacional de Pesquisas Espaciais através da plataforma Toposat. As imagens do Google Earth possibilitaram a combinação da localização dos pontos e da concentração de cada elemento analisado.

\subsection{MÉTODO DE ANÁLISE}

O estudo iniciou-se com a realização de monitoramento da qualidade dos sedimentos de uma região, dentro da bacia Tietê-Batalha. Foram definidos os corpos hídricos que seriam monitorados, os pontos e a frequência das. No total foram sete córregos definidos e os pontos de coleta foram marcados por GPS. A amostras de sedimentos foram coletadas em pontos próximos à margem e a jusante dos afluentes próximos a barragem da Usina Hidrelétrica de Promissão (Figura 2). Nota-se que a escolha dos pontos nos monitoramentos seguiram o fluxo natural das correntes e consideraram as mudanças hidrossedimentológicas avaliando as contribuições que cada região, com o objetivo de obter amostras reais dos corpos hídricos.Para o georreferenciamento da localização dos pontos de amostragens foi utilizado um Receptor GPS Garmin Etrex 20. 


\section{ANAP Brasil \\ ISSN 1984-3240 \\ v. 10, n. 21}

\section{REVISTA CIENTIFICA 2017}

Figura 2: Locais de retiradas de amostras na Bacia Hidrográfica Tietê-Batalha, próximo à barragem de Promissão.

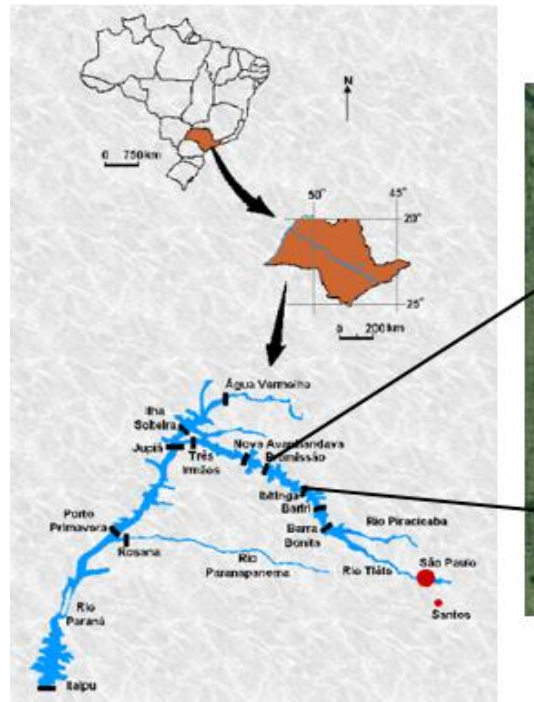

Fonte: Imagem retirada do GoogleEarth.

As amostragens de sedimentos foram obtidas nos meses de setembro e dezembro de 2013, todas no período matutino, com a preocupação de manter-se um padrão no horário das coletas. A Tabela 1 apresenta a descrição dos pontos de coletas de ambos os materiais e suas respectivas coordenadas geográficas.

Tabela 1: Descrição dos pontos de coletas e suas respectivas coordenadas geográficas.

\begin{tabular}{lllll}
\hline \multirow{2}{*}{ Margem } & Ponto & Local de amostragem & \multicolumn{2}{c}{ Coordenadas aproximadas (UTM) } \\
\cline { 4 - 5 } & & & Latitude & Longitude \\
\hline \multirow{3}{*}{ Direita } & P1 & Córrego do Pinheiro & $651281,37 \mathrm{E}$ & $7633064,30 \mathrm{~S}$ \\
& P2 & Rio Barra Mansa & $646506,49 \mathrm{E}$ & $7638755,15 \mathrm{~S}$ \\
& P3 & Ribeirão dos Bagres & $638417,95 \mathrm{E}$ & $764076,95 \mathrm{~S}$ \\
& P4 & Rio da Fartura & $633518,65 \mathrm{E}$ & $7644931,98 \mathrm{~S}$ \\
\hline \multirow{2}{*}{ Esquerda } & P5 & Córrego da Queixada & $630630,93 \mathrm{E}$ & $7639868,48 \mathrm{~S}$ \\
& P6 & Rio Dourado & $634411,68 \mathrm{E}$ & $7636100,81 \mathrm{~S}$ \\
& P7 & Córrego do Esgotão & $648469,39 \mathrm{E}$ & $7630199,65 \mathrm{~S}$ \\
\hline
\end{tabular}

Fonte: CARDOSO,2014.

O primeiro passo foi a tabulação de todos os valores gerados pelos monitoramentos de sedimentos. Os resultados das coletas foram separados por ano, mês e ponto para, posteriormente, serem criadas tabelas utilizando o software Microsoft Excel contendo a localização dos pontos e os valores dos parâmetros amostrados. Após a criação das tabelas, pode-se lançar essas informações no software versão QGIS 2.18 .9 e assim combiná-las com a imagem georreferenciada de satélite da região estudada. 
Com os dados carregados dentro do software, pode-se fazer várias combinações e comparações entre os elementos monitorados associando-os com a influência do escoamento superficial nas concentrações dos elementos, com o relevo da área, o uso e ocupação do solo, a presença de impactos ambientais, atividades econômicas da região, assim como a verificação dos limites dos parâmetros nas legislações ambientais.

\subsection{ANÁLISE DE METAIS}

As contaminações por metais no meio ambiente têm como principais fontes os pesticidas, queima de combustíveis fósseis, fertilizantes agrícolas e resíduos industriais, que possuem em suas composições o zinco $(\mathrm{Zn})$, cobre $(\mathrm{Co})$, chumbo $(\mathrm{Pb})$, níquel $(\mathrm{Ni})$, cádmio $(\mathrm{Cd})$, entre outros, sendo que alguns representam maiores riscos ambientais como o mercúrio, chumbo, arsênio e cádmio, devido à frequência de uso industrial e a alta toxidade (BELLUTA et al., 2008). Estes elementos são dispersos na atmosfera ou lixiviados nos corpos d'água e findam na deposição nos sedimentos, se bioacumulando e transformando assim, concentrações conhecidas como normais em concentrações tóxicas ao homem e a biota; e seus efeitos permanecem ao longo do tempo, mesmo após cessar as emissões (TAVARES et al.,1992). Neste contexto, o presente estudo processou os dados obtidos através do monitoramento dos seguintes parâmetros: Al, $\mathrm{Cd}, \mathrm{Pb}, \mathrm{Zn}, \mathrm{Cr}, \mathrm{Co}, \mathrm{Cu}, \mathrm{Fe}, \mathrm{Hg}, \mathrm{Mn}$, Ni e K. Adicionou-se o elemento potássio devido a vocação sucroalcooleira da região estudada, considerando o uso indiscriminado de adubos químicos e o reuso da vinhaça na fertirrigação pode elevar os níveis de potássio na água e consequentemente, nos sedimentos (CARDOSO, 2014).

\section{RESULTADOS}

A Tabela 2 ilustra os resultados analíticos dos sedimentos da primeira e da segunda coleta. Foram considerados como padrão os limites estabelecidos pela Resolução CONAMA 344/2004 para as amostras de sedimento.

Os valores encontrados para o alumínio, ferro, manganês, níquel, potássio e zinco foram os únicos detectados e permaneceram abaixo do Limite de Detecção (L.D.) do método para todas as amostras de sedimentos. Os que não foram estão apresentados como Não Detectáveis (N.D.).

À partir do lançamento desses dados no QGIS, aplicou-se as ferramentas do programa que auxiliaram na avaliação ambiental e na qualidade dos sedimentos. Na Figura 3 é exibido o Modelo Digital de Elevação do Terreno (MDT) e representa a magnitude altimétrica da área de estudo.

Ressalta-se que esta imagem 3D do relevo foi extrapolada no eixo z em 15 vezes para facilitar a visualização da áreas mais íngremes da bacia, por se tratar de uma área com pouca variação de cotas. Nota-se as áreas em vermelho são as principais contribuintes de escoamento superficial, sendo importantes pontos de observação de uso e ocupação do solo, de taxas de escoamento superficial, sendo quanto maior o índice de escoamento, menor é a taxa de infiltração no solo. 


\section{ANAP Brasil \\ ISSN 1984-3240 \\ v. 10, n. 21}

\section{REVISTA CIENTIFICA 2017}

Se essas áreas apresentarem ausência de cobertura vegetal ou manejo do solo inadequado ocorrerá o arraste das camadas superficiais do solo, que incorporarão no sedimentos do corpo hídrico respectivo de cada ponto.

Tabela 2 - Resultados analíticos de metais das amostras de sedimento das duas coletas realizadas.

\begin{tabular}{|c|c|c|c|c|c|c|c|c|c|}
\hline \multirow{2}{*}{$\begin{array}{l}\text { Metais } \\
\left(\mathrm{mg} \mathrm{kg}^{-1}\right)\end{array}$} & \multirow{2}{*}{ Coleta } & \multicolumn{7}{|c|}{ Pontos amostrais } & \multirow{2}{*}{$\begin{array}{r}\text { VMP } \\
\left(\mathrm{mg} \mathrm{kg}^{-1}\right)\end{array}$} \\
\hline & & P1 & & P3 & P4 & P5 & P6 & P7 & \\
\hline \multirow{2}{*}{ Alumínio } & 1 & 2495,90 & 19750,00 & 6370,70 & 5810,10 & 4410,20 & 32874,00 & 2958,20 & \multirow{4}{*}{0,60} \\
\hline & 2 & 632,10 & 10796,00 & 7714,90 & 2293,50 & 5608,70 & 5922,70 & 1601,80 & \\
\hline \multirow{2}{*}{ Cádmio } & 1 & N.D. & N.D. & N.D. & N.D. & N.D. & N.D. & N.D. & \\
\hline & 2 & N.D. & N.D. & N.D. & N.D. & N.D. & N.D. & N.D. & \\
\hline \multirow{2}{*}{ Chumbo } & 1 & 1,57 & 1,41 & 1,79 & 2,06 & 1,68 & 2,13 & 1,58 & \multirow{2}{*}{35,00} \\
\hline & 2 & N.D. & 4,60 & 3,10 & 1,80 & 3,20 & 2,50 & N.D. & \\
\hline \multirow{2}{*}{ Cobalto } & 1 & N.D. & 4,67 & 1,42 & 1,34 & 2,49 & 8,39 & N.D. & \\
\hline & 2 & N.D. & 4,00 & 1,90 & 1,00 & 1,50 & 4,00 & 4,10 & \\
\hline \multirow{2}{*}{ Cobre } & 1 & 0,93 & 11,60 & 2,39 & 1,91 & 2,63 & 21,70 & 0,93 & \multirow{2}{*}{34,70} \\
\hline & 2 & 0,50 & 7,20 & 5,00 & 1,60 & 2,30 & 5,20 & 1,60 & \\
\hline \multirow{2}{*}{$\begin{array}{l}\text { Crômio } \\
\text { Total }\end{array}$} & 1 & 7,22 & 45,84 & 28,24 & 22,39 & 16,21 & 58,73 & 3,81 & \multirow{2}{*}{37,30} \\
\hline & 2 & 3,80 & 40,70 & 21,60 & 21,30 & 14,00 & 25,50 & 11,60 & \\
\hline \multirow{2}{*}{ Ferro Total } & 1 & 2045,50 & 15164,00 & 5333,60 & 4293,90 & 6299,00 & 20183,00 & 2218,40 & \\
\hline & 2 & 1920,00 & 23162,00 & 12304,00 & 7822,20 & 5694,80 & 15011,00 & 5313,50 & \\
\hline \multirow{2}{*}{ Manganês } & 1 & 33,21 & 188,40 & 69,61 & 69,85 & 184,70 & 408,49 & 37,79 & \\
\hline & 2 & 28,40 & 140,30 & 75,20 & 62,90 & 70,50 & 242,50 & 54,40 & \\
\hline \multirow{2}{*}{ Mercúrio } & 1 & N.D. & N.D. & N.D. & N.D. & N.D. & N.D. & N.D. & \multirow{2}{*}{0,17} \\
\hline & 2 & N.D. & N.D. & N.D. & N.D. & N.D. & N.D. & N.D. & \\
\hline \multirow{2}{*}{ Níquel } & 1 & 0,61 & 13,84 & 1,76 & 1,22 & 1,86 & 21,89 & 1,07 & \multirow{2}{*}{18,00} \\
\hline & 2 & 0,90 & 9,10 & 5,70 & 2,30 & 3,00 & 9052,00 & 3,00 & \\
\hline \multirow{2}{*}{ Potássio } & 1 & 54,09 & 985,15 & 113,24 & 58,13 & 310,52 & 733,95 & 56,85 & \\
\hline & 2 & 27,40 & 445,10 & 158,50 & 53,60 & 181,60 & 1120,50 & 234,40 & \\
\hline \multirow{2}{*}{ Zinco } & 1 & N.D. & N.D. & N.D. & N.D. & N.D. & N.D. & N.D. & \multirow{2}{*}{123,00} \\
\hline & 2 & 0,90 & 7,30 & 4,70 & 22,30 & 4,10 & 7,00 & 2,60 & \\
\hline
\end{tabular}

Legenda: N.D.- Não Detectado.

VMP = Valor Máximo Permitido.

1- Primeira coleta realizada em 24/09/2014.

2- Segunda coleta realizada em 23/12/2014.

Fonte: CARDOSO, 2014. 


\section{ANAP Brasil \\ ISSN 1984-3240 \\ v. 10, n. 21}

\section{REVISTA CIENTIFICA 2017}

Figura 3: Modelo Digital de Elevação do Terreno (MDT) e os pontos de coletas.

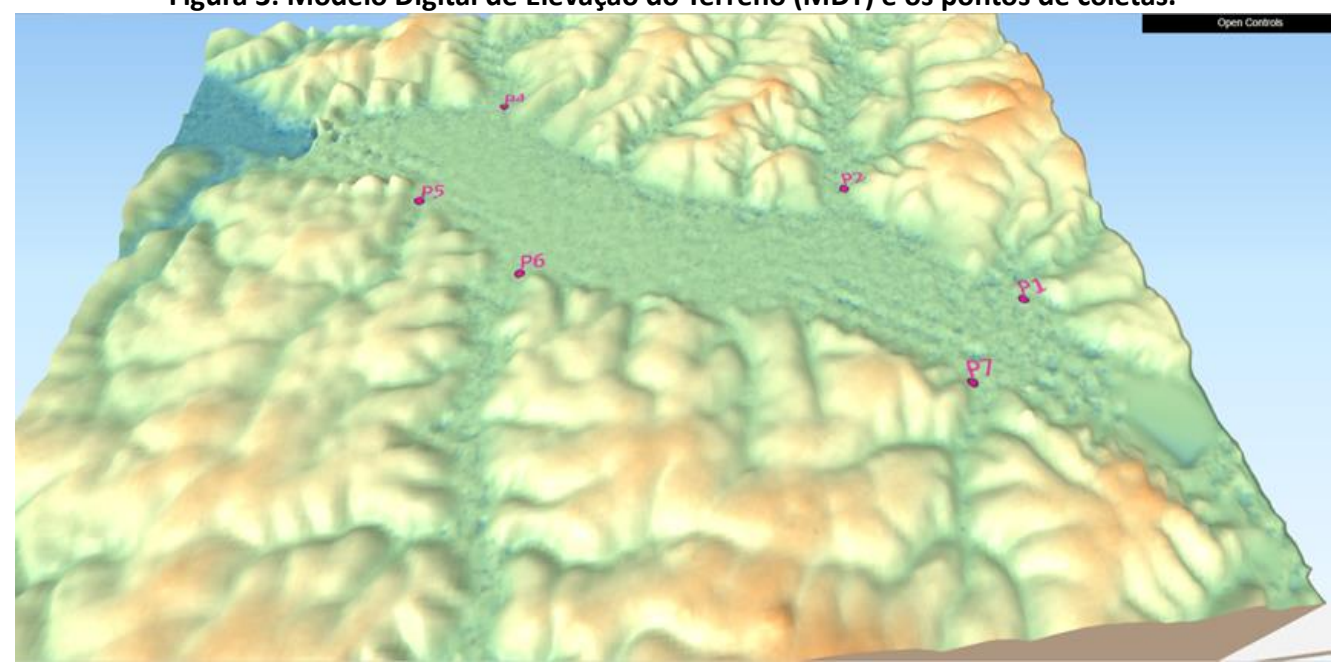

Os resultados apontaram que o níquel aumentou sua concentração no Ponto 2 e no Ponto 6, sendo que somente no ponto 6 o Valor Máximo Permitido (VMP) de $18 \mathrm{mg} \mathrm{kg}^{-1}$ foi excedido com 21,9 $\mathrm{mg} \mathrm{kg}^{-1}$.Os processos erosivos dos solos e rochas, lançamento de efluentes industriais e chorume são as formas mais comuns do níquel ser carreado para os rios e córregos. As particulas são transportadas para os rios juntamente com material orgânico e se depositam nos sedimentos, permanencendo no meio e podendo agregar-se à biota local. Deve-se lembrar que o níquel esta presente de forma natural na biosfera, no ar, na água e no solo. A Figura 4 exibe o comportamente do níquel nas amostras, sendo que na maioria dos pontos a concentração apresentou-se inferior ao VMP, sendo exceção o ponto 6, que variou de forma inesperada entre as duas coletas. Esta discrepância de valores pode ter sido gerada por uma aplicação de fertilizantes nos dias anteriores à coleta, pois a atividade econômica é fortemente sucroalcooleira, e o níquel presente nesses produtos pode ter sido carreado para o leito do rio e se depositado na superficie sedimentar.Uma característica fundamental é que os afluentes dos Pontos 6 e 7 são constituídos de Argissolo Vermelho Escuro, ou seja, solos argilosos susceptíveis à erosão. 


\section{ANAP Brasil \\ ISSN 1984-3240 \\ v. 10, n. 21}

\section{REVISTA CIENTIFICA 2017}

Figura 4: Comparação entre os valores do níquel (azul) e o respectivo limite estabalecido pela legislação (vermelho).

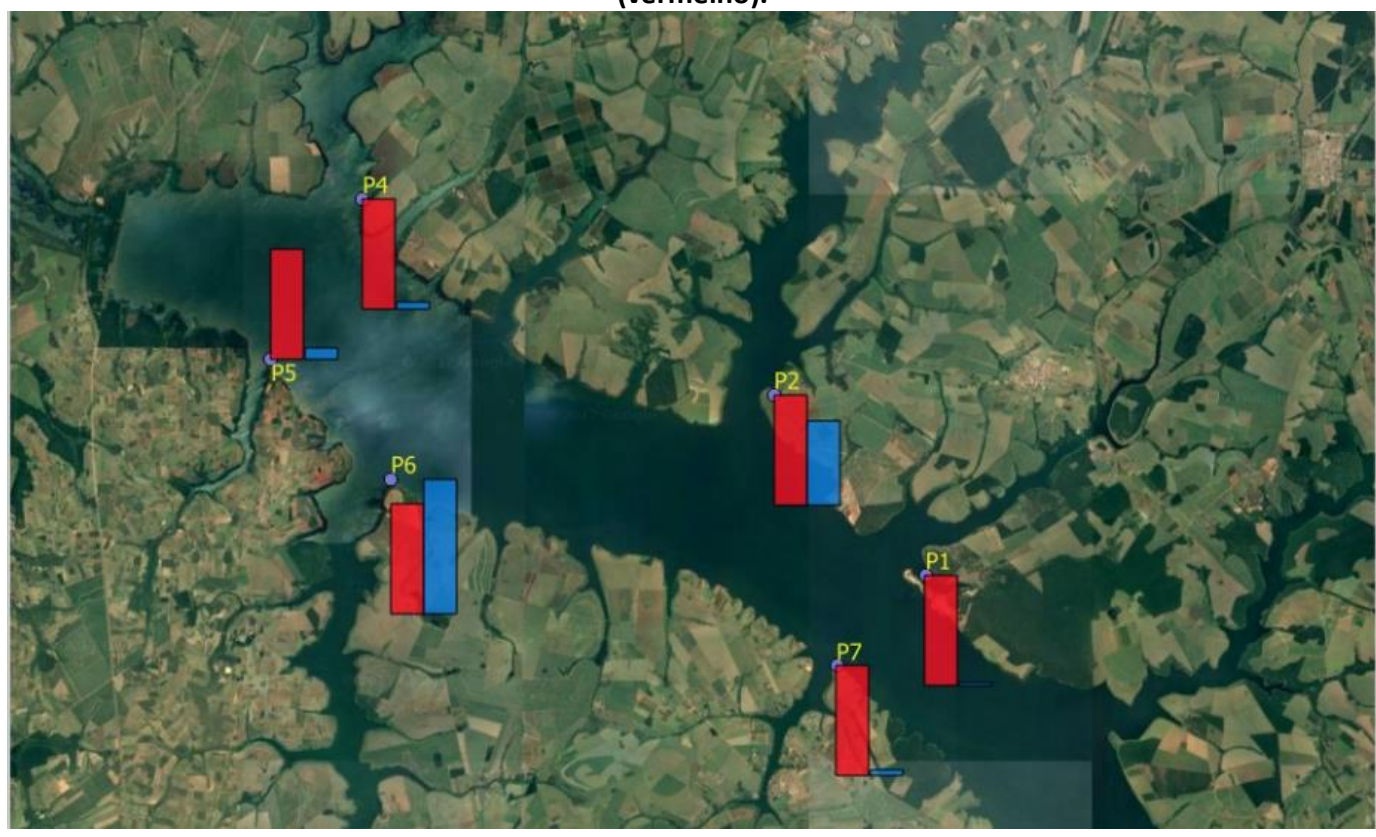

As análises apontaram um alto nivel de aluminio em todas as amostras coletadas, sendo possível associá-las com o tipo de rocha da região, tornando-se disponível no ambiente na forma de material particulado muito provavelmente devido aos processos naturais como erosões naturais no solo, mineração, atividades agrícolas, combustão de carvão e gases vulcânicos; o alumínio fica disponível em forma de material particulado.

O crômio foi outro parâmetro que excedeu o VMP tanto no ponto 2 quanto no ponto 6, conforme ilustra a Figura 5. O crômio pode ser proveniente de lançamentos de esgoto sem tratamento, uma vez que é característico dos lodos das Estações de tratamento conterem altos níveis desse elemento. Ou seja, toda a carga de esgoto sem tratamento das cidades, a montante, chegam até esses pontos e as partículas se depositam ao longo do percurso. 


\section{ANAP Brasil \\ ISSN 1984-3240 \\ v. 10, n. 21}

\section{REVISTA CIENTIFICA 2017}

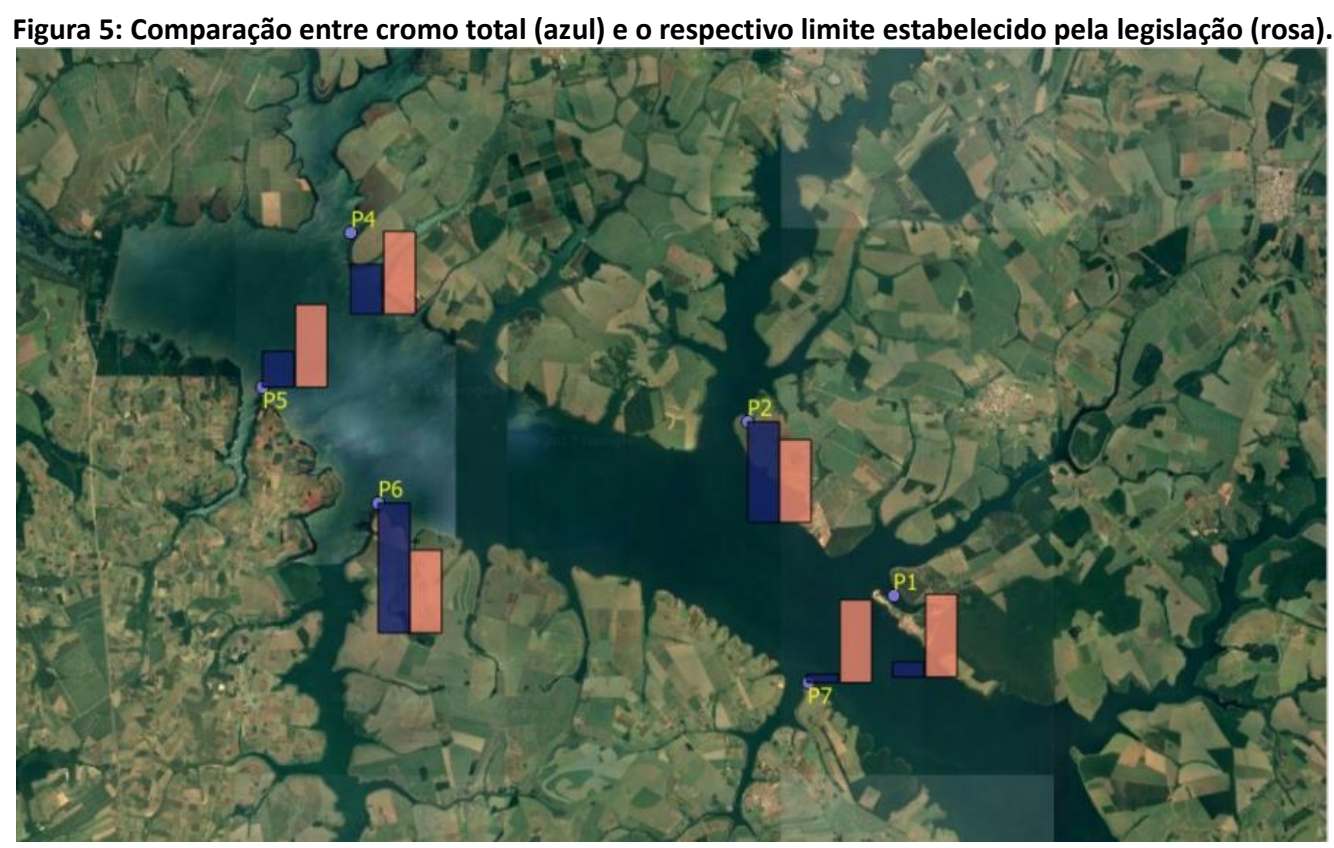

\section{CONCLUSÃO}

A ferramenta QGIS mostrou-se muito eficiente no propósito de auxiliar na avaliação ambiental da qualidade dos sedimentos da micro bacia do Tietê Batalha. Com as imagens de satélites foi possível expandir o campo de visão no que diz respeito às características do relevo, tipos de culturas cultivadas, contribuições do escoamento superficial para os níveis de metais.

Dentre os pontos analisados, o Ponto 2 e o Ponto 6 apresentaram-se como os mais vulneráveis a contaminação devido às proporções elevadas em todos os elementos analisados.

Todas as análises revelaram a presença de metais nos sedimentos, mas todos com os valores abaixo dos níveis críticos estabelecidos para sedimentos e encontram-se distribuídos em formas químicas pouco disponíveis, portanto há pouca transferência para as plantas e peixes da micro bacia.

A característica da região como sucroalcooleira contribui para o maior uso de defensivos agrícolas, cujo efeito na acumulação de metais nos sedimentos se faz presente devido ao arraste periódico da camada do solo pela erosão.

E finalmente, é importante considerar que o tipo de solo e o uso e ocupação da região contribuem com o aumento da concentração de metais nos sedimentos.

\section{REFERÊNCIAS BIBLIOGRÁFICAS}

ALMEIDA, D.F., 2010. Gestão Ambiental dos Sedimentos de Corrente do Rio São Francisco na Região de Três Marias/ Minas Gerais. Tese de Doutorado. UNIVERSIDADE FEDERAL DE MINAS GERAIS. 2010.

AMORIM, E.L.C. Monitoramento Ambiental. Unidade Acadêmica Centro de Tecnologia - CTEC, 2012.

BELLUTA, Ivalde et al. Impactos provocados por metais potencialmente tóxicos dissolvidos em água e em 


\section{ANAP Brasil \\ ISSN 1984-3240 \\ v. 10, n. 21}

\section{REVISTA CIENTIFICA 2017}

sedimentos no Córrego do Cintra - Botucatu-SP. Salusvita, Bauru. 2008

BOSSLE, Renato Cabral. QGIS e geoprocessamento na prática. São José dos pinhais: Edição do Autor, 2015. 232. 2015.

CARDOSO, A.M.T. Verificação da qualidade da água e dos sedimentos no rio Tietê entre as barragens de Promissão e lbitinga / Ana Maria Taddei Cardoso, $2014.77 \mathrm{f}$.

CÂMARA, G. et al. Introdução à Ciência da Geoinformação.2001. Disponível em: < http://www.dpi.inpe.br/gilberto/livro/introd/> , Acesso em 27 Abr 2016.

CÂMARA, G.; ORTIZ, M. J. Sistemas de informação geográfica para aplicações ambientais e cadastrais: uma visão geral. In: CONGRESSO BRASILEIRO DE ENGENHARIA AGRÍCOLA: CARTOGRAFIA, SENSORIAMENTO E GEOPROCESSAMENTO, 27., 1998, Poços de Caldas. Anais... Lavras: UFLA, 1998. p. 59-88.

CBH Tietê-Batalha. Relatório de Situação dos Recursos Hídricos da UGRHI-16. Comitê da Bacia Hidrográfica do Tietê-Batalha, 2010. Disponível em: <http://www.comitetb.sp.gov.br/index.php?tab=1\&acao=com12>, Acesso em 14 Out de 2017.

CONAMA, Conselho Nacional do Meio Ambiente, Resolução $\mathbf{n}^{\mathbf{0}} \mathbf{4 5 4}$, de 01 de novembro de 2012 . Estabelece as diretrizes gerais e os procedimentos mínimos para a avaliação do material a ser dragado em águas jurisdicionais brasileiras e dá outras providências, 2012.

LIMA, E. de A. M. Avaliação da qualidade dos sedimentos e prognóstico geoquímico ambiental da zona estuarina do rio Botafogo, Pernambuco. 2008. Tese de doutorado.

M. Casanova, G. Câmara, C. Davis, L. Vinhas, G. Ribeiro (org), "Bancos de Dados Geográficos”. São José dos Campos, MundoGEO, 2005.

NASCIMENTO, W. M.; VILLAÇA, M. G. Bacias hidrográficas: planejamento e gerenciamento. Revista Eletrônica da Associação dos Geógrafos Brasileiros- Seção Três Lagoas, v. 01, n. 07, p. 102-120, 2008.

POLETO, C. Fontes potenciais e qualidade dos sedimentos fluviais em suspensão em ambiente urbano. Porto Alegre. 2005. 137f. Tese (Doutorado em Recursos Hídricos e Saneamento Ambiental) - Universidade Federal do Rio Grande do Sul. 2005.

W Salomons, U Förstner . Trace metal analysis on polluted sediments.Part II: Evaluation of environmental impact. Editora Krumbein,1980.

TUCCI, C.M; MENDES, A.C. Avaliação ambiental integrada de bacia hidrográfica / Ministério do Meio Ambiente / SQA. - Brasília: MMA, 2006. 302 p. : 302 p. :

TAVARES, T.M, CARVALHO, F.M. Quim, Nova, Vol.15, No.2, 1992. Avaliação d exposição de populações humanas a metais pesados no meio ambiente: exemplo do recôncavo Baiano. 1992.

TUCCI, C. E. M. 1997. Hidrologia: ciência e aplicação. 2.ed. Porto Alegre: ABRH/Editora da UFRGS, 1997.

VILLELA, Swami Marcondes; MATTOS, Arthur. Hidrologia Aplicada. São Paulo: McGraw-HIl do Brasil, 1975. 